\title{
MARINE RESERVES: RATES AND PATTERNS OF RECOVERY AND DECLINE OF PREDATORY FISH, 1983-2000
}

\author{
Garry R. Russ ${ }^{1,3}$ And Angel C. Alcala ${ }^{2}$ \\ ${ }^{1}$ School of Marine Biology and Aquaculture, James Cook University of North Queensland, Townsville, \\ Queensland, 4811, Australia \\ ${ }^{2}$ Silliman University Angelo King Center for Research and Environmental Management, Silliman University, \\ Dumaguete City, 6200, Philippines
}

\begin{abstract}
The application of no-take marine-reserve status to an area is expected to increase spawning-stock biomass of species targeted by fisheries, and to help sustain fisheries external to the reserve. However, empirical evidence on rates and patterns of increase of density and biomass of target species following closures to fishing, and of decrease when reserve status is removed, remains rare. We have monitored density and biomass of large predatory coral-reef fish (Serranidae [Epinephelinae], Lutjanidae, Lethrinidae, and Carangidae, as a group) visually in two small no-take marine reserves and at two control (open to fishing) sites in the Philippines from 1983 to 2000. At Sumilon reserve a complex history of management allowed 13 measurements of density and biomass at durations of reserve protection of $-3 \mathrm{yr}$ (i.e., fished for 3 years after reserve status removed) to $9 \mathrm{yr}$. At Apo reserve 13 measurements were taken at durations of protection of 1-18 yr. We recorded 11 significant $(P<0.05)$ changes in density at the four sites over the 17 years, three declines and eight increases. All three significant declines occurred when reserve protection was removed. Four of the eight significant increases occurred when reserve status was applied. This represents some of the best evidence currently available that application of marine-reserve status causes increases in abundance of target species. Three of the four significant increases in density required 4-6 yr of protection. Significant positive linear correlations of mean density of large predators against years of reserve protection were observed at both reserves. The pattern of increase of mean biomass against years of reserve protection was exponential, with biomass initially increasing more slowly than density. Density and biomass increased by factors of 12.2 and 17.3, respectively, during $18 \mathrm{yr}$ of continuous protection in Apo reserve. At Sumilon Island three bouts of unregulated fishing of 1.5-3 yr duration eliminated density and biomass gains accumulated over 5-9 yr of marine reserve protection.
\end{abstract}

Key words: biomass; census, visual; coral-reef fish; decline rates; fish density; fisheries management; fishing impact; indicator species; marine reserves; Philippines; predators, large; recovery rates.

\section{INTRODUCTION}

No-take marine reserves are defined as permanent spatial closures to fishing (Roberts and Polunin 1991, Dugan and Davis. 1993, Allison et al. 1998, Murray et al. 1999, Dayton et al. 2000, NRC 2001). A major expectation of marine reserves as fisheries management tools is that they will sustain fisheries external to them by containing a high abundance of species targeted by fisheries (relative to fished areas) and become net exporters of adults and propagules (Russ 2002). Use of marine reserves as a fisheries management tool is advocated widely in the coral-reef literature (Alcala and Russ 1990, Roberts and Polunin 1991, Bohnsack 1996, Russ 2002). In many developing nations with coral reefs, there are few other alternative management options (Alcala and Russ 1990).

Manuscript received 20 November 2001; revised 17 December 2002; accepted 20 March 2003. Corresponding Editor: L. B. Crowder.

${ }^{3}$ E-mail: garry.russ@jcu.edu.au
At first sight, the evidence that marine reserves increase the density and biomass of target species on reefs significantly appears considerable. In reviews of the evidence, Roberts and Polunin (1991), Dugan and Davis (1993), Rowley (1994), Bohnsack (1996, 1998), Roberts (1997) and Halpern (2003), for example, all suggested that the evidence for enhanced abundance of target species in marine reserves was good. However, the majority of this evidence still involves comparisons of abundance of target species at the one time at sites with and without marine-reserve protection (Halpern and Warner 2002, Russ 2002, Halpern 2003). These comparisons almost invariably are confounded by differences in habitat, history, and larval supply between reserve and fished locations. In fact, the locations of many reserves are selected specifically because they are areas of high-quality habitat and high abundance of fish in the first place (Russ 2002). This inevitable confounding of spatial comparisons of reserve and fished sites at one time was stressed long ago by Russ (1985), Roberts and Polunin (1991), Jones et al. (1992), 

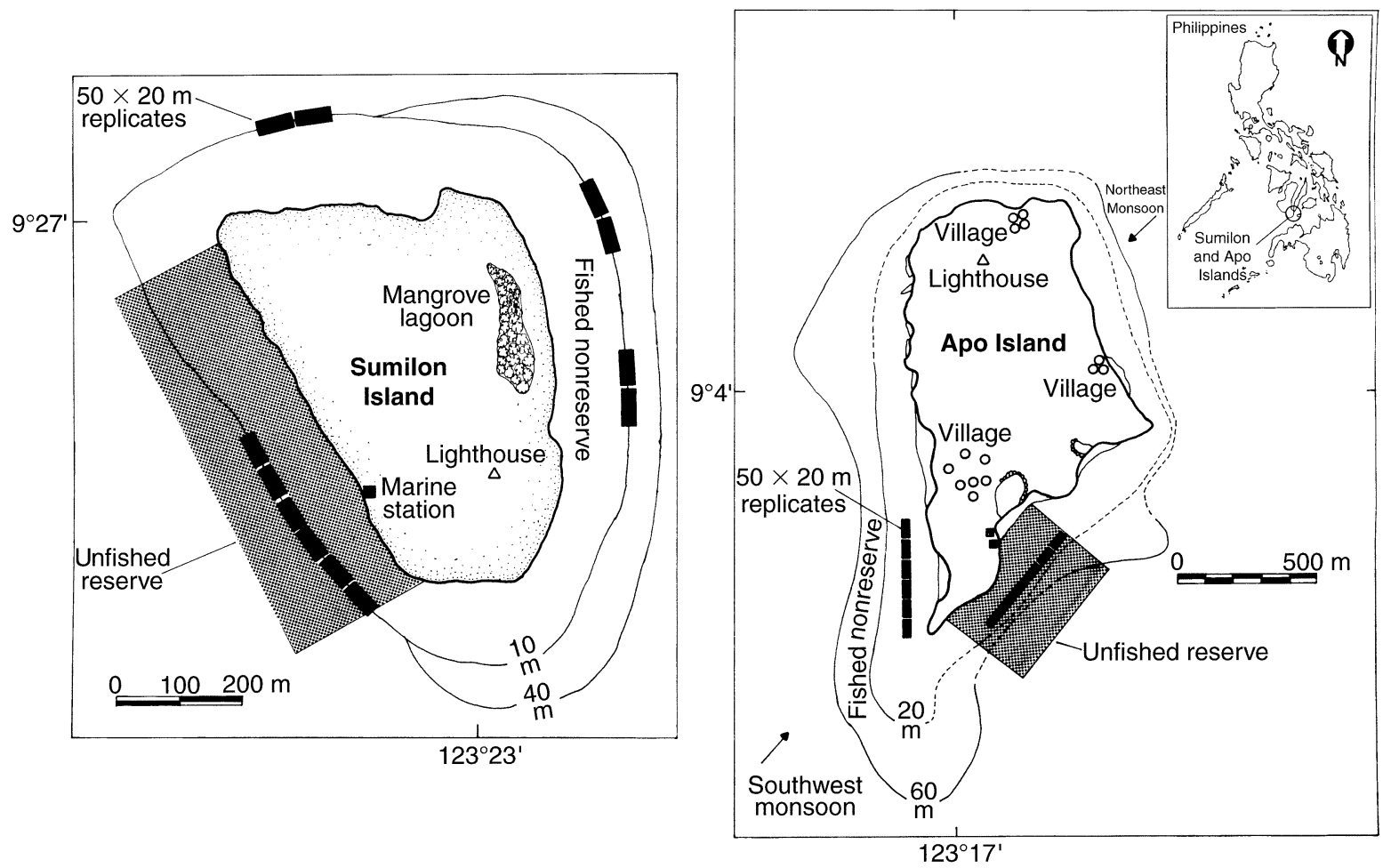

FIG. 1. Map showing the location of Sumilon and Apo islands, central Philippines, and the location of the unfished reserve areas (shaded) and the fished nonreserve areas. The positions of the six $50 \times 20 \mathrm{~m}$ replicate underwater visualcensus plots surveyed at each sampling site and time are shown as solid rectangles. Mainstream currents come from the north at each island.

and Dugan and Davis (1993). Many authors have pointed out the need for before-after, control-impact pair (BACIP) experimental designs to unequivocally conclude that marine reserves were the cause of higher abundance of target species within them relative to fished areas (Jones et al. 1992, Russ 2002). Such experimental designs, coupled with long-term monitoring, are still not available in the marine-reserve literature (Russ 2002, Halpern 2003).

The lack of appropriate experimental designs means that we still can rarely conclude unequivocally that higher abundance of target species was caused by application of marine-reserve status. The paucity of longterm monitoring of abundance of target species inside and outside marine reserves means that we still know remarkably little about the rates and patterns of increase of abundance of target species following application of reserve status (Russ and Alcala 1996a, 1998, McClanahan 2000, Jennings 2001). Furthermore, our knowledge of how quickly high abundance of target species can be lost if reserve status is removed is also limited (Russ and Alcala 1996a).

We have been monitoring populations of exploited coral-reef fish regularly in two small marine reserves in the Philippines for 17 years (1983-2000). These reserves, at Sumilon and Apo islands (Fig. 1), have been protected and monitored for longer than most other marine reserves in the world. In addition, Sumilon Island has had a complex history of management that has resulted in marine-reserve protection being applied and removed to the same site on multiple occasions over the 17-yr study (Fig. 2). Russ and Alcala (1996a) reported on the first decade of monitoring of abundance of large predatory fish in these reserves. We argued in that paper that rates of recovery of fish biomass would likely occur on decadal time scales. Here we present empirical evidence derived from the visual monitoring of density and biomass of large predatory coral-reef fish in these two marine reserves and at two control sites in the Philippines over the period 1983 to 2000.

The specific questions we address are:

1) Can application of marine reserve status cause a significant increase in density and biomass of large predatory fish?

2) What are the rates and patterns of increase of density and biomass of such fish following application of reserve status?

3) How quickly can gains in density and biomass of such fish be lost if reserve protection is removed?

\section{Methods \\ Study sites}

The study was carried out at two islands in the central Visayas region of the Philippines (Fig. 1). The islands 


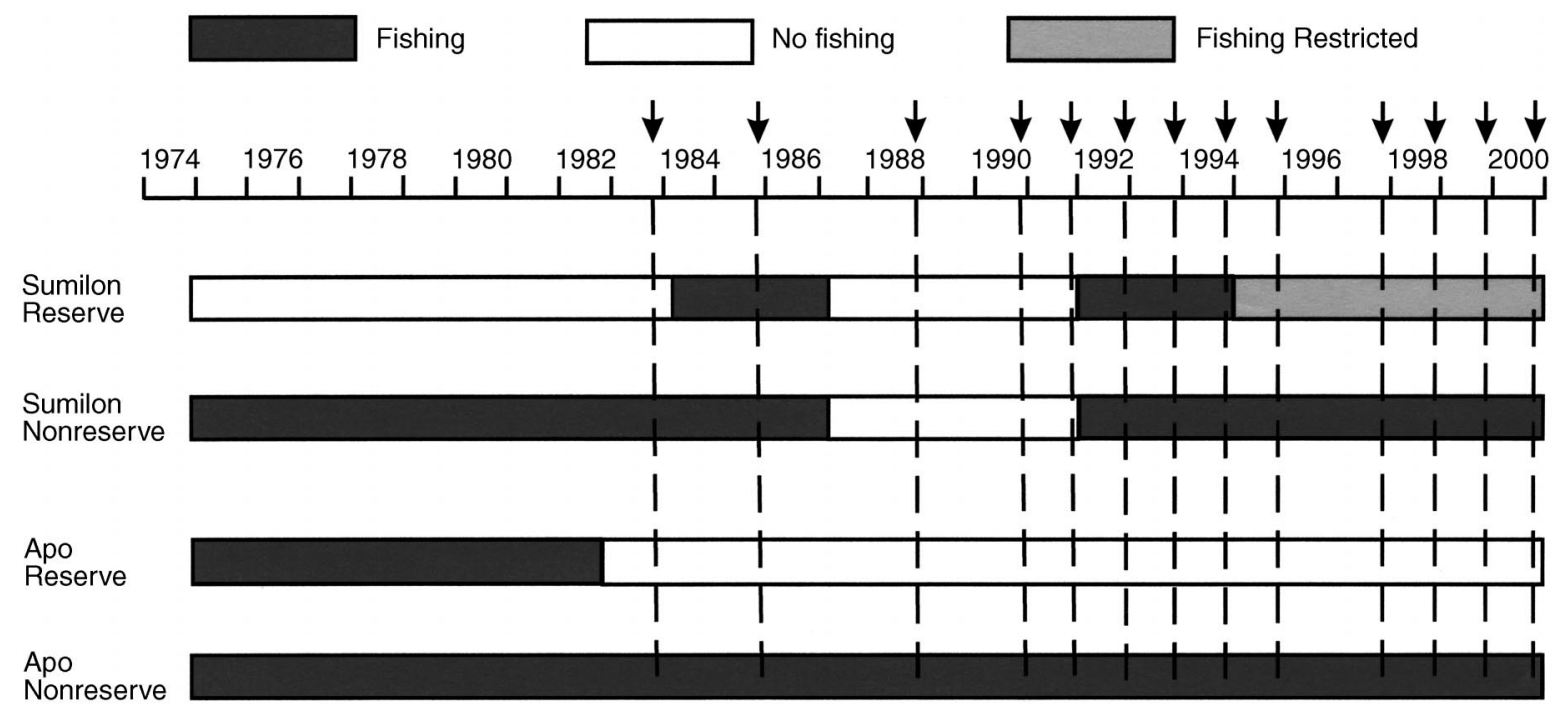

FIG. 2. Schematic diagram showing the history of marine-reserve protection and fishing at Sumilon and Apo islands, central Philippines (from 1974 to 2000). "No Fishing" indicates the periods when the sites were fully protected. "Fishing" indicates when sites were open to municipal fishers. "Fishing Restricted" indicates a period when all fishing techniques but hook and line fishing were banned. The arrows and dashed lines indicate the 13 sampling times.

were Sumilon Island, southeast of Cebu $\left(9^{\circ} 21^{\prime} \mathrm{N}\right.$, $\left.123^{\circ} 23^{\prime} \mathrm{E}\right)$, and Apo Island, southeast of Negros $\left(9^{\circ} 4^{\prime}\right.$ $\left.\mathrm{N}, 123^{\circ} 16^{\prime} \mathrm{E}\right)$. Russ and Alcala $(1996 a, 1998)$ provide a detailed description of the study sites. Briefly, Sumilon Island had a marine reserve established on its western side in December 1974. Apo Island had a marine reserve established on its southeastern side in late 1982. Sumilon Island is a coralline island of $0.23 \mathrm{~km}^{2}$, surrounded by a fringing coral reef of $0.5 \mathrm{~km}^{2}$ to the $40-\mathrm{m}$ isobath. Apo Island is a mainland island of 0.7 $\mathrm{km}^{2}$ surrounded by $1.06 \mathrm{~km}^{2}$ of fringing coral reef to the $60-\mathrm{m}$ isobath $\left(0.7 \mathrm{~km}^{2}\right.$ to the $20-\mathrm{m}$ isobath).

The Sumilon reserve is a $0.75-\mathrm{km}$ section $(\sim 25 \%$ of the coral reef area) of the western side of the island (Fig. 1). The area of the reserve to $500 \mathrm{~m}$ from shore is 37.5 ha. The reef crest in the reserve is at a depth of 2 to $3 \mathrm{~m}$ at mean tidal level. The reef crest and slope in the southern section of the reserve are mostly consolidated limestone with relatively high coral cover (Russ and Alcala 1998). The nonreserve site at Sumilon Island has a reef "crest" at a depth of 5 to $7 \mathrm{~m}$, and this crest and the reef slope were covered with sand and a lower cover of living coral than the reserve site (Russ and Alcala 1998). The Apo reserve is a 0.45-km section $(\sim 10 \%$ of the coral reef area) of the southeastern side of the island (Fig. 1). The area of the reserve to $500 \mathrm{~m}$ from shore is 22.5 ha. The reef crest is at a depth of 6 to $7 \mathrm{~m}$ and there was a high percentage cover of hard corals on the reef crest and slope. The nonreserve site at Apo Island has a crest at a depth of 5 to $7 \mathrm{~m}$. The crest and slope were consolidated limestone overlaying a base of volcanic rock. There was a relatively high percentage cover of living corals, particularly soft corals (Russ and Alcala 1998).
Sumilon reserve has had a complex history of management over the period 1974 to 2000 (Fig. 2) (Russ and Alcala 1999). The reserve was protected for $9.5 \mathrm{yr}$ (1974-1984) from municipal fishers ( 100 fishers who fished the nonreserve side of the island regularly with hook and line, spears, $\sim 100$ bamboo fish traps, and gill nets). The reserve was then "pulse fished" for $\sim 3 \mathrm{yr}$ (1984-1986). This fishing included use of explosives and drive nets ("muro-ami") in 1984-1985 (see Russ and Alcala 1989, Alcala and Russ 1990). The reserve was protected again for almost 5 yr (1987-1991), opened to municipal fishing for $3 \mathrm{yr}$ (1992-1994), then had fishing restricted (all fishing banned except hook and line) for 6 yr (1995-2000) (Fig. 2). Sumilon nonreserve was open to the municipal fishers from 1974 to 1986 , closed to fishing for $5 \mathrm{yr}(1987-1991)$ and then opened again to municipal fishers for 9 yr (19922000) (Fig. 2). The nonreserve side of Sumilon island has produced high yields of reef fish and is known to be subject to high fishing pressure (Alcala and Russ 1990).

Apo Island has approximately 500 permanent residents. The Apo reserve (= sanctuary) was protected by the resident community from 1982, although the legal framework for the protected area was not in place until August 1985 (Russ and Alcala 1999). Protection of the marine reserve has been very successful, with a local marine-management committee overseeing enforcement during the period 1982-2000 (Fig. 2). The nonreserve area was open to municipal fishing (hook and line, gill nets, bamboo traps much like those used at Sumilon, and spears) throughout the study (Fig. 2). A marine management plan for Apo Island was introduced in 1986 (Russ and Alcala 1999). This banned all 


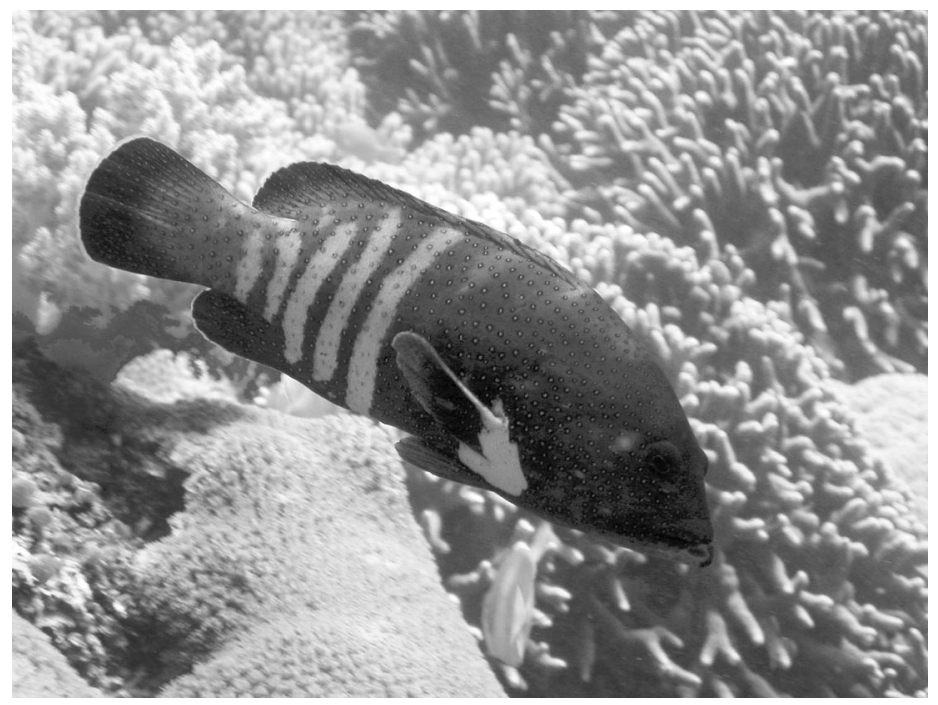

Plate 1. A grouper (Cephalopholis argus [Serranidae: Epinephelinae]) on the coral reef slope of Apo no-take reserve, central Philippines. Photo by Rene Abesamis.

forms of destructive fishing gears (explosives, drive nets, small-mesh nets, poisons) from the entire island, and banned fishing by nonresidents. Thus from 1986 onwards, only traditional fishing methods were used outside the reserve (= sanctuary), and only residents fished the reef. The major activity of the 500 residents is fishing, with the nonreserve area fished by $\sim 200$ fishers during this period. This area has produced high yields of reef fish and is known to be subject to high fishing pressure (Alcala and Luchavez 1981, White and Savina 1987, Bellwood 1988, Maypa et al. 2002). The management histories of the four sites over the 17-yr period (see Fig. 2) provide a unique natural experiment to investigate the effects of marine-reserve protection and fishing on the abundance of target species of fish.

\section{Method of visual census}

Quantitative estimates of abundance of coral-reef fishes were made at the two reserves (and at two nonreserve sites-see Fig. 1) using a technique of visual census (Russ and Alcala 1996a). Six replicate $50 \times 20$ $\mathrm{m}$ plots were censused on the reef slopes of each reserve and nonreserve in December or November of 1983, 1985, 1988, 1990-1995 and 1997-2000. The same replicate locations were censused each year (see Fig. 1). The replicates were clustered in the southern section of Sumilon reserve to ensure sampling as consistent a habitat as possible (Fig. 1). The reef slope of this reserve becomes increasingly sandy in the northern section. The small size of the reserves, combined with accurate maps of features on the coast, buoy sites and underwater features, permitted placement of each replicate to within $\pm 5-10 \mathrm{~m}$ of its previous position each year. The $50 \times 20 \mathrm{~m}$ replicate size was originally chosen to census 178 species of coral-reef fishes in 18 families (Russ and Alcala 1989). These species had a wide range of body and home-range sizes, and the 50 $\times 20 \mathrm{~m}$ size was chosen to accommodate this variety, rather than to maximize precision of counts for any particular family or species. The current study presents data on a total of 45 taxa in the families Serranidae (Epinephelinae) (22 spp.; see Plate 1), Lutjanidae (13 spp.), Lethrinidae (9 spp.), and Carangidae (all species combined) (Table 1). These taxa were collectively designated as "large predators." All individuals of these families were identified to species (except Carangidae), and counted in each replicate plot. Carangidae were lumped into one group due to initial difficulties in identification of fish to species level. However, this group consists of $\sim 6$ species, with 2 species (Caranx sexfasciatus and $C$. melampygus) dominant. Total length (TL) was estimated to within $\pm 2 \mathrm{~cm}$ for all Serranidae, and to within $\pm 5 \mathrm{~cm}$ for Lutjanidae, Lethrinidae, and Carangidae. Juveniles $(<10 \mathrm{~cm}$ TL) were not counted. An estimate of biomass was calculated from density and size-structure data. Lengths were converted to mass using published length-mass relationships (Froese and Pauly 1997). Length-mass relationships for many of the 45 taxa were not available. Thus we used an "average" relationship for each Family (Table 1), and kept this consistent across the $17 \mathrm{yr}$ of monitoring. No data on temporal variation in these length-mass relationships exist at our sites. If such variation occurred, it would be likely to be minimal. Russ and Alcala (1996a) provide a detailed account of the method of visual census of the $50 \times 20 \mathrm{~m}$ replicate areas. A census took $\sim 40-50$ minutes to complete. Six replicate censuses were made at each site, each separated by a distance of $\sim 10 \mathrm{~m}$. The same replicate areas were censused at each site in each sampling year (see Fig. 1). The replicate censuses were placed within $\sim 10 \mathrm{~m}$ of each other to ensure that six replicates would sample most of the Apo reserve and the majority of the southern portion of Sumilon reserve.

\section{Data analysis}

Comparisons of density and biomass at the four sites over the 13 times are presented graphically. Statistical 
TABLE 1. The taxa of reef fish, grouped by family, that made up the category "large predators" in this study at Sumilon Island and Apo Island (central Philippines), together with an indication of any sites where a taxon attained a density equal to or greater than one of three arbitrary densities at some time during the study.

\begin{tabular}{|c|c|c|c|}
\hline Species & Site $(s) \dagger$ & $\begin{array}{l}\text { Length-mass } \\
\text { relationship } \ddagger\end{array}$ & $n \S$ \\
\hline $\begin{array}{l}\text { Serranidae (Epinephelinae) } \\
\text { Anyperodon leucogrammicus } \\
\text { Atheloperca rogaa } \\
\text { Cephalopholis argus } \\
\text { C. boenack } \\
\text { C. cyanostigma } \\
\text { C. leopardus } \\
\text { C. microprion } \\
\text { C. miniatus } \\
\text { C. sexmaculatus } \\
\text { C. urodelus } \\
\text { C. spp. } \\
\text { Epinephelus caeruleopunctatus } \\
\text { E. fasciatus } \\
\text { E. fuscoguttatus } \\
\text { E. ongus } \\
\text { E. spp. } \\
\text { Plectropomus areolatus } \\
\text { P. laevis } \\
\text { P. leopardus } \\
\text { P. oligocanthus } \\
\text { Variola albimarginata } \\
\text { V. louti }\end{array}$ & $\begin{array}{l}\text { AR } \\
\boldsymbol{A R}, \mathrm{SR}, \boldsymbol{S} \boldsymbol{R} \boldsymbol{R} \\
\ldots \\
\ldots \\
\ldots \\
\text { SR } \\
\text { ANR, SNR, SR } \\
\text { AR, SNR, SR } \\
\ldots \\
\ldots \\
\ldots \\
\ldots \\
\ldots \\
\text { SNR } \\
\ldots \\
\ldots \\
\ldots \\
\ldots \\
\ldots \\
\text { SNR } \\
\text { SNR }\end{array}$ & $M=0.016 \times L^{3.011}$ & 2 \\
\hline $\begin{array}{l}\text { Lutjanidae } \\
\text { Aphareus furcatus } \\
\text { Lutjanus argentimaculatus } \\
\text { L. bohar } \\
\text { L. decussatus } \\
\text { L. fulviflamma/ehrenbergi } \\
\text { L. fulvus } \\
\text { L. gibbus } \\
\text { L. lutjanus } \\
\text { L. monostigma } \\
\text { L. rivulatus } \\
\text { L. russelli } \\
\text { L. spp. }\end{array}$ & $\begin{array}{l}\ldots \\
\ldots \\
\text { SR } \\
\text { ANR, SNR, SR } \\
\text { SR } \\
\text { SR } \\
\text { AR } \\
\text { SNR } \\
A R, S R \\
\ldots \\
\ldots \\
\ldots\end{array}$ & $M=0.019 \times L^{3.025}$ & 3 \\
\hline
\end{tabular}

Macolor macularis/niger $\quad$ ANR, $A R$, SNR, SR

Lethrinidae

Lethrinasus atkinsoni

L. erythracanthus

L. erythropterus

L. harak

L. lentjan

L. obsoletus

L. olivaceus

L. spp

Monotaxis grandoculis

$M=0.026 \times L^{2.961}$

AR, SR

...

ANR, SR

ANR

ANR

SNR

AR, SR

Carangidae

"Carangids",

ANR, $\boldsymbol{A R}, \boldsymbol{S N R}, \boldsymbol{S R}$

$$
M=0.022 \times L^{2.941} \quad 2
$$

$\dagger \mathrm{ANR}=$ Apo nonreserve; $\mathrm{AR}=$ Apo reserve; $\mathrm{SNR}=$ Sumilon nonreserve; $\mathrm{SR}=$ Sumilon reserve. Boldface italic type indicates a mean of $\geq 2$ fish $/ 1000 \mathrm{~m}^{2}$, boldface type indicates a mean of $\geq 1 \mathrm{fish} / 1000 \mathrm{~m}^{2}$, and standard lightface type indicates a mean of $\geq 0.5 \mathrm{fish} / 1000 \mathrm{~m}^{2}$.

\$ The relationships used to convert length to mass for each Family are shown.

$\S$ The number of species used to calculate the "average" length-mass relationship for each family.

comparisons of density and biomass at the four sites over the 13 times were made using univariate, repeatedmeasures ANOVA. Our sampling design in 1983 was straightforward, containing reserve $(=$ unfished) and fished sites at each of two islands. However, since the status of the protected site at Sumilon changed four times during the period 1983 to 2000 (Fig. 2) and the status of Sumilon nonreserve changed twice, the "reserve" factor and the "island" factor were treated as a single, fixed-factor "site" with four levels. Nested 
TABLE 2. Results of univariate repeated-measures ANOVAs of density and biomass of large predatory reef fish; values given are $F$ ratios.

\begin{tabular}{lccc}
\hline \hline Variate & $\begin{array}{c}\text { Sites, } \\
(\mathrm{df}=3,20)\end{array}$ & $\begin{array}{c}\text { Times, } \\
(\mathrm{df}=12,240)\end{array}$ & $\begin{array}{c}\text { Site } \times \text { Time } \\
(\mathrm{df}=36,240)\end{array}$ \\
\hline Density & $60.31 * * *$ & $13.40 * * *$ & $3.92 * * *$ \\
Biomass & $46.72 * * *$ & $8.45 * * *$ & $5.30 * * *$ \\
\hline
\end{tabular}

Notes: Probability values for effects of Time and Time $\times$ Site interaction are Greenhouse-Geiser adjusted $P$ values. All variates were $\log _{10}(x+1)$ transformed. $* * * P<0.001$.

within each site were six plots (a random factor). The third factor in the design was the repeated-measure time with 13 levels. A repeated-measure ANOVA was used because the same plots were sampled each year. A single "missing data" point (only five replicate plots were taken at Apo nonreserve in 1983) was calculated by unweighted means analysis (Winer 1971). Before proceeding with the ANOVA, the data were examined for homogeneity of variance $(P<0.05)$ by Cochrans test (Underwood 1981), for excessive skewness and outliers by examining Box plots, for strong positive correlations between means and variances, and for normality. Data were transformed $\left(\log _{10}(x+1)\right)$ when necessary. The assumption of sphericity in univariate repeated-measures ANOVA was overcome by using Greenhouse-Geisser adjusted $P$ values for the time factor and the site $\times$ time interactions. This analysis showed that the site $\times$ time interaction was highly significant for each variate and the Greenhouse-Geisser adjusted $P$ values did not differ greatly from the unadjusted values (Table 2). Post-hoc comparisons of means following these ANOVAs resulted in a large number of comparisons with no inherent interest (e.g., different sites compared at different times). In addition, since the protected status of two sites changed over time (Fig. 2), the comparisons of greatest interest were those between times for each site. Thus a repeated measures ANOVA was performed for each site separately (factors "plots" and "time," defined above) and the error variances from these analyses were used in posthoc comparisons of means (Tukey's hsd tests, $P<0.05$ ) for each time at each site.

Census times in December or November of 1983, 1985, 1988, 1990-1995 and 1997-2000 corresponded to periods of reserve protection of $1,3,6,8,9,10,11$, $12,13,15,16,17$, and $18 \mathrm{yr}$ at Apo and 9, -1.5, 2, $4,5,-1,-2,-3,1,3,4,5$, and $6 \mathrm{yr}$ at Sumilon, respectively (see Fig. 2). Note that the period 19952000 at Sumilon reserve was treated as a period of reserve protection, since fishing was restricted, with just one gear, hook and line, allowed. Mean density (mean of six replicate plots in any year) of large predatory fish was plotted against years of reserve protection for both reserves. Simple linear-regression techniques were used to test if significant relationships existed between the variates. The relationship between mean biomass and years of protection was not linear at either reserve. Exponential curves were fitted to the data for mean biomass per unit area against years of reserve protection, to test if a significant relationship existed between the variates.

\section{RESULTS}

Eleven significant $(P<0.05)$ changes in density of large predatory fish were recorded at the four sites over the $17 \mathrm{yr}$ - three declines and eight increases (Fig. 3, Table 3). All three significant declines occurred when reserve protection was removed, twice within the Sumilon reserve $(1985,1992)$ and once at the Sumilon nonreserve site (1992) (Fig. 3, Table 3). Four of the eight significant increases in density occurred when reserve status was applied (Fig. 3, Table 3). These increases were at the Sumilon reserve (1985-1991 and 19931995), the Sumilon nonreserve (1985-1991), and Apo reserve (1983-1988). Three of these four significant increases in density required $4-6 \mathrm{yr}$ of protection. Another two significant increases in density occurred as protection continued at the Sumilon reserve (19972000) and Apo reserve (1988-2000) (Fig. 3, Table 3). On two occasions, density increased significantly in the absence of marine-reserve status (Sumilon nonreserve 1994-1997 and Apo nonreserve 1991-1998) (Fig. 3, Table 3).

Substantial temporal change in biomass of large predators occurred also (Fig. 4), and tended to reflect changes in density, except that biomass did not increase as rapidly as density initially following application of reserve status (Figs. 3 and 4, Table 3). Six significant $(P<0.05)$ changes in biomass of large predatory fish were recorded at the four sites over the $17 \mathrm{yr}$-two declines and four increases (Fig. 4, Table 3). Both significant declines occurred when reserve protection was removed from the Sumilon reserve (1985) and the Sumilon nonreserve (1992) (Fig. 4, Table 3). Three of the four significant increases in biomass occurred when reserve status was applied (Fig. 4, Table 3). These increases were at the Sumilon reserve (1997-2000), the Sumilon nonreserve (1985-1991), and Apo reserve (1983-1988). Another significant increase in biomass occurred as protection continued in the Apo reserve (1988-2000) (Fig. 4, Table 3). At Sumilon reserve, biomass did not recover significantly from the pulsefishing event of 1985 until 14 yr later (1999). This was despite two significant increases in density following reapplication of reserve status $(1987,1995)$. Biomass had not risen to 1983 levels 17 yr later in 2000 (Fig. 4 , Table 3), with periods of fishing occurring in 19841986 and 1992-1994.

The slower rate of increase of biomass relative to density following application of marine-reserve status was caused mainly by the time delay between closure and the period of maximum individual growth (Russ and Alcala 1996a). Thus, even though fishing mortality was reduced or eliminated in reserves, there appears 


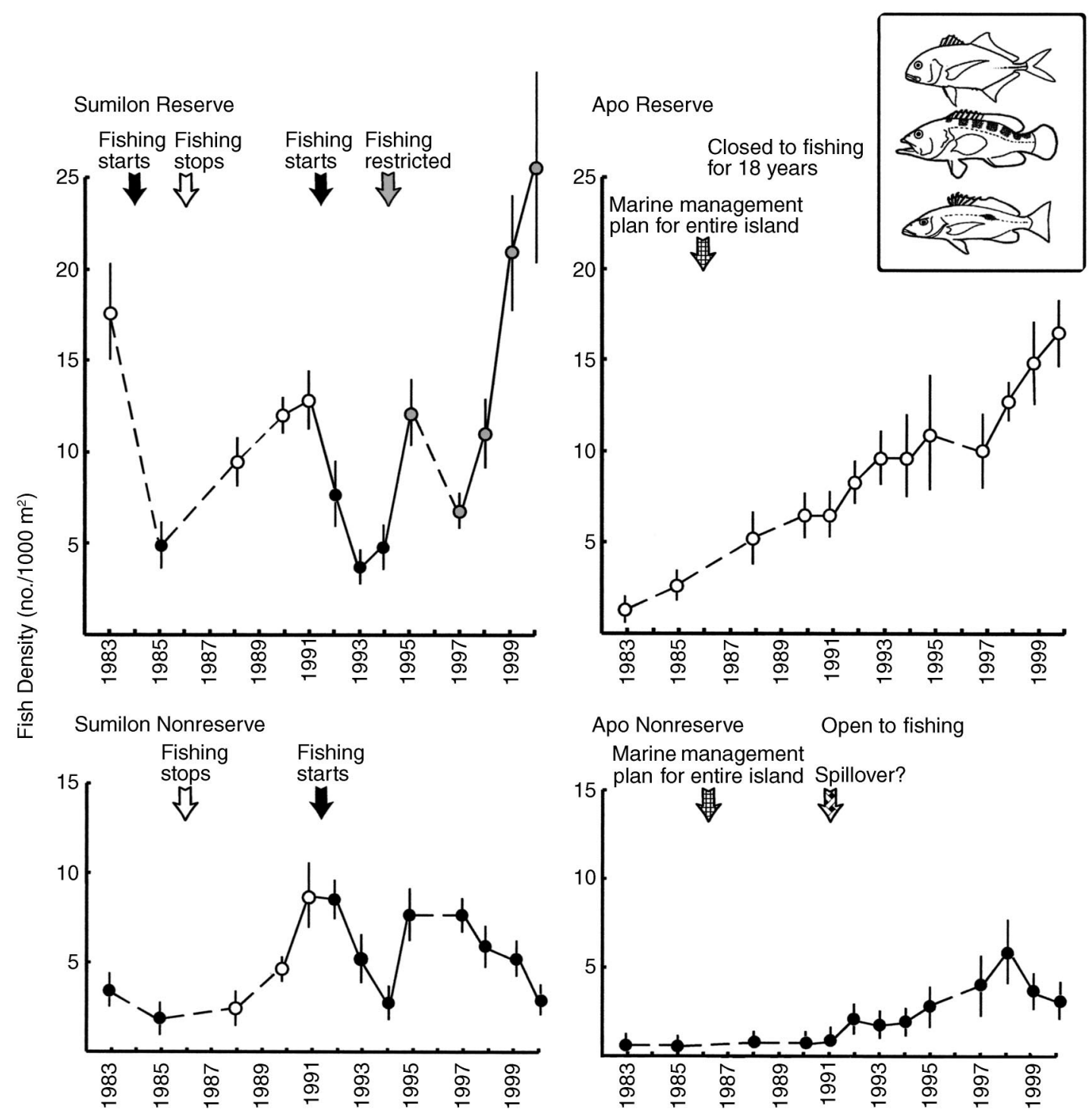

FIG. 3. Density (number/1000 $\mathrm{m}^{2}$ ) of large predatory reef fish (Families Serranidae [Epinephelinae], Lutjanidae, Lethrinidae, and Carangidae as a group) at four sites at the 13 sampling times. Data are means \pm 1 SE. Black arrows indicate when fishing began, white arrows indicate when fishing stopped at the two Sumilon sites, and gray arrows indicate when fishing was restricted at Sumilon reserve (all fishing banned except hook and line). Patterned arrows indicate the introduction of the marine management plan at Apo Island. Fishing stopped at Apo reserve in 1982, and the site remained protected throughout the study. Apo nonreserve was open to fishing throughout the study.

to be a considerable time delay before populations of large predatory fish attain size structures with high mean and modal sizes. Within Apo reserve, it took 18 $\mathrm{yr}$ of continuous, effective protection to increase the modal size of large predatory fish by $15 \mathrm{~cm}$ total length (TL) (Fig. 5). Within Sumilon reserve modal size of predatory fish was $36-40 \mathrm{~cm}$ TL following $9 \mathrm{yr}$ of protection. Modal length was subsequently reduced 15 cm by fishing between 1983 and 1988 in the Sumilon reserve and did not increase over the next $12 \mathrm{yr}$, despite subsequent periods of protection of $5 \mathrm{yr}$ (1987-1991) and 6 yr (1995-2000) (Fig. 5).
The clearest examples of density increasing more rapidly than biomass in this study occurred when "recruitment pulses" (large, rapid addition of small, presumably recently settled, individuals to the benthic fish populations) were observed. The significant increases in density in the Sumilon reserve during the periods 1985-1991 and 1994-1995 (Fig. 3, Table 3) were strongly influenced by $200 \%$ and $300 \%$ density increases in one year of Cephalopholis sexmaculatus (between 1990-1991 and 1994-1995, respectively). A similar recruitment pulse occurred in the Sumilon nonreserve between 1994 and 1995 (when this site was 
TABLE 3. Summary of major changes in density and biomass of large predatory fish at the four study sites over time.

\begin{tabular}{|c|c|c|c|c|}
\hline \multirow{2}{*}{$\begin{array}{l}\text { Site and } \\
\text { time period }\end{array}$} & \multirow{2}{*}{$\begin{array}{c}\text { Reserve } \\
\text { status, RS } \dagger\end{array}$} & \multicolumn{2}{|c|}{ Change } & \multirow{2}{*}{$\begin{array}{c}\text { Probable cause } \\
\text { of change }\end{array}$} \\
\hline & & Density & Biomass & \\
\hline \multicolumn{5}{|l|}{ Sumilon reserve } \\
\hline $1983-1985$ & removed after $9 \mathrm{yr}$ & down $82 \%(*)$ & down $85 \%(*)$ & RS removed \\
\hline $1985-1991$ & applied for $5 \mathrm{yr}$ & up $160 \%(*)$ & up $66 \%(*)$ & RS applied \\
\hline $1991-1993$ & removed for $2 \mathrm{yr}$ & down $69 \%(*)$ & down $70 \%(*)$ & RS removed \\
\hline $1983-1993$ & removed, applied, removed & down $92 \%(*)$ & down $92 \%(*)$ & RS removed, applied, removed \\
\hline 1993-1995 & restricted fishing applied & up $200 \%(*)$ & up $207 \%$ (Ns) & RS applied \\
\hline $1997-2000$ & restricted fishing continued & up $290 \%(*)$ & up $420 \%(*)$ & RS continued plus recruitment pulse \\
\hline \multicolumn{5}{|c|}{ Sumilon nonreserve } \\
\hline 1985-1991 & applied for $5 \mathrm{yr}$ & up $420 \%(*)$ & up $310 \%(*)$ & RS applied \\
\hline 1991-1994 & removed for $3 \mathrm{yr}$ & down $69 \%(*)$ & down $78 \%(*)$ & RS removed \\
\hline 1994-1997 & open to fishing & up $190 \%(*)$ & up $224 \%$ (NS) & recruitment pulse \\
\hline $1997-2000$ & open to fishing & down $73 \%$ (NS) & down $66 \%$ (Ns) & fished down \\
\hline \multicolumn{5}{|l|}{ Apo reserve } \\
\hline $1983-1988$ & applied for $6 \mathrm{yr}$ & up $300 \%(*)$ & up $302 \%(*)$ & RS applied \\
\hline $1988-2000$ & RS continued & up $203 \%(*)$ & up $330 \%(*)$ & RS continued \\
\hline $1983-2000$ & RS for $17 \mathrm{yr}$ & up $1115 \%(*)$ & up $1630 \%(*)$ & long-term RS \\
\hline \multicolumn{5}{|l|}{ Apo nonreserve } \\
\hline $1991-1998$ & open to fishing & up $580 \%(*)$ & up $695 \%$ (NS) & MMP and spillover $\$$ \\
\hline $1998-2000$ & open to fishing & down $47 \%$ (NS) & down $40 \%$ (Ns) & fished down \\
\hline
\end{tabular}

Notes: Results of Tukey's HSD tests for pairwise differences between times in density and biomass are shown.

$* P=0.05 ;$ NS $=$ not significant.

$\dagger$ Reserve status refers to application or removal of the "no-take" status. See Fig. 2.

$\$$ MMP = marine management plan, applied to whole of Apo Island beginning in 1986. Spillover refers to possible export of post-settlement fish from reserve to nonreserve.

open to fishing), with the density of C. argus increasing $1000 \%$ (from 1 to 11 fish in the six replicates) in $1 \mathrm{yr}$. In all of these cases, density increases were not accompanied by significant increases in biomass because most of the fish were new recruits of small body mass.

On two other occasions at Sumilon Island, recruitment pulses resulted in significant increase in both density and biomass. A $330 \%$ increase in density of $\mathrm{Lu}$ tjanus ehrenbergi was recorded in one year (19981999 ) in the Sumilon reserve (note rapid rise in Fig. $3)$. The increase in density of this species was so dramatic between 1997 and 2000 that the density in 2000 was $820 \%$ higher than the mean density of this species for the 15-yr period 1983-1997. Even though most of the individuals were 15-25 cm TL (Fig. 5), they were so abundant that their presence resulted in a significant increase in biomass as well. A $160 \%$ increase in density of $C$. argus and C. sexmaculatus combined was recorded in one year (1990-1991) in the Sumilon nonreserve. This recruitment pulse occurred in the fifth year of protection, and resulted in significant increases in both density and biomass. No similar recruitment pulses occurred at Apo Island for the $17 \mathrm{yr}$ of the study.

The delay in growth of individual fish once recruited, results in different rates and patterns of increase of density relative to biomass following application of reserve status. The data from the reserves are expressed in terms of mean density or biomass vs. years of reserve protection (with negative numbers indicating years of fishing), rather than in chronological order, in Fig. 6. The relationships between mean density of large pred- ators and years of protection from fishing (ranging from -3 to 9 years at Sumilon reserve, 1 to 18 years at Apo reserve) were linear and highly significant (Fig. 6a). The rate of increase was 1.45 fish per $1000 \mathrm{~m}^{2}$ per year at Sumilon and 0.81 fish per $1000 \mathrm{~m}^{2}$ at Apo reserve (Fig. 6). The relationships between mean biomass of large predators and years of protection were exponential and highly significant (Fig. 6b). Exponential models explained $14 \%$ and $11 \%$ more of the variance than linear models at Sumilon and Apo reserves, respectively. Note, however, that the exponents of the exponential relationships in Fig. 6 are both $<0.2$, with the time unit in years. Mean density and biomass were still increasing after 9 and 18 years of marine-reserve protection at Sumilon and Apo reserves, respectively, with little evidence of either density or biomass approaching an asymptote (Fig. 6).

\section{DISCUSSION}

The first expectation of marine reserves as a fisheries management tool is that they will reduce fishing mortality (Russ 2002). Fishing mortality is rarely measured in reserve and fished sites over time, but can be inferred to differ based on knowledge of the effectiveness of protection. The Apo no-take reserve has had very effective protection since 1982, because it is actively and diligently protected by a community-based marinemanagement committee (Russ and Alcala 1999). The reserve is within $500 \mathrm{~m}$ of the main village on Apo Island. Sumilon reserve had very effective protection from 1974 to 1983 , because a caretaker lived in front 


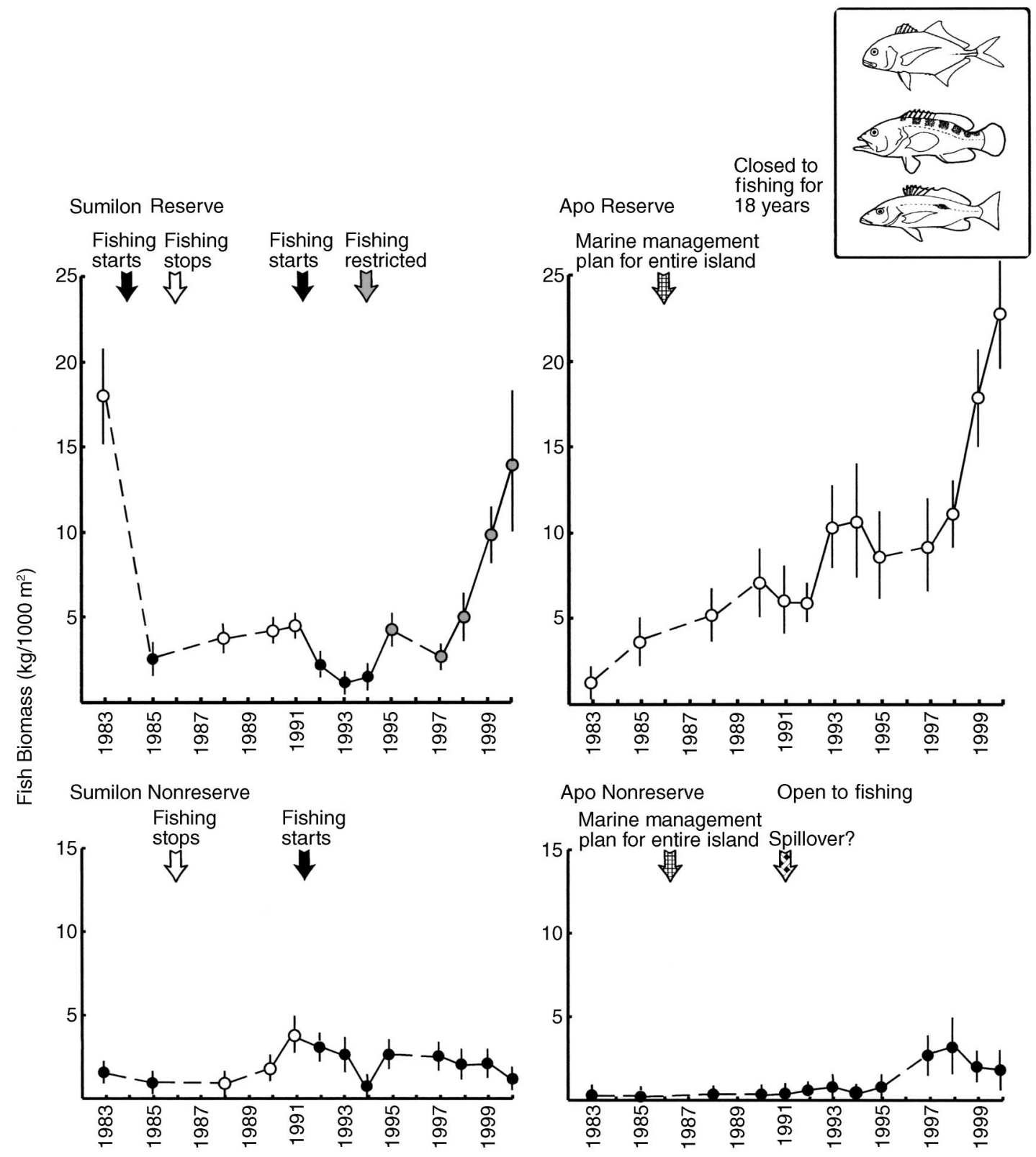

FIG. 4. Biomass $\left(\mathrm{kg} / 1000 \mathrm{~m}^{2}\right)$ of large predatory reef fish (Families Serranidae [Epinephelinae], Lutjanidae, Lethrinidae, and Carangidae as a group) at four sites at the 13 sampling times. Data are means \pm 1 SE. Format as in Fig. 3.

of the reserve, and actively guarded it (Russ and Alcala 1999). The local mayors of the two towns controlling fishing at Sumilon Island banned fishers from fishing or visiting the island from 1987 to 1991 (Russ and Alcala 1999). A caretaker again lived in front of the reserve and actively guarded it during 1995-2000. Thus we are confident that the periods of application of reserve status at the two islands (Fig. 2) were periods of effective protection. There is little doubt that fishers displaced when the reserves were first established would have concentrated their fishing effort in the nonreserve areas of both islands. However, long-term data have shown that very high yields of reef fish have been maintained or even increased in these nonreserve areas at Sumilon island over a decade (Alcala and Russ 1990) and at Apo island over two decades (Maypa et al. 2002).

Density of large predatory fish increased significantly over eight different periods of time, and decreased significantly over three time periods, in this study (Fig. 3, Table 3). Four of the eight density increases occurred in areas by applying fishery closures (Sumilon reserve 1987-1991, 1993-1995; Sumilon nonreserve 1987-1991, Apo reserve 1983 onwards). Significant increases were detected on two other oc- 


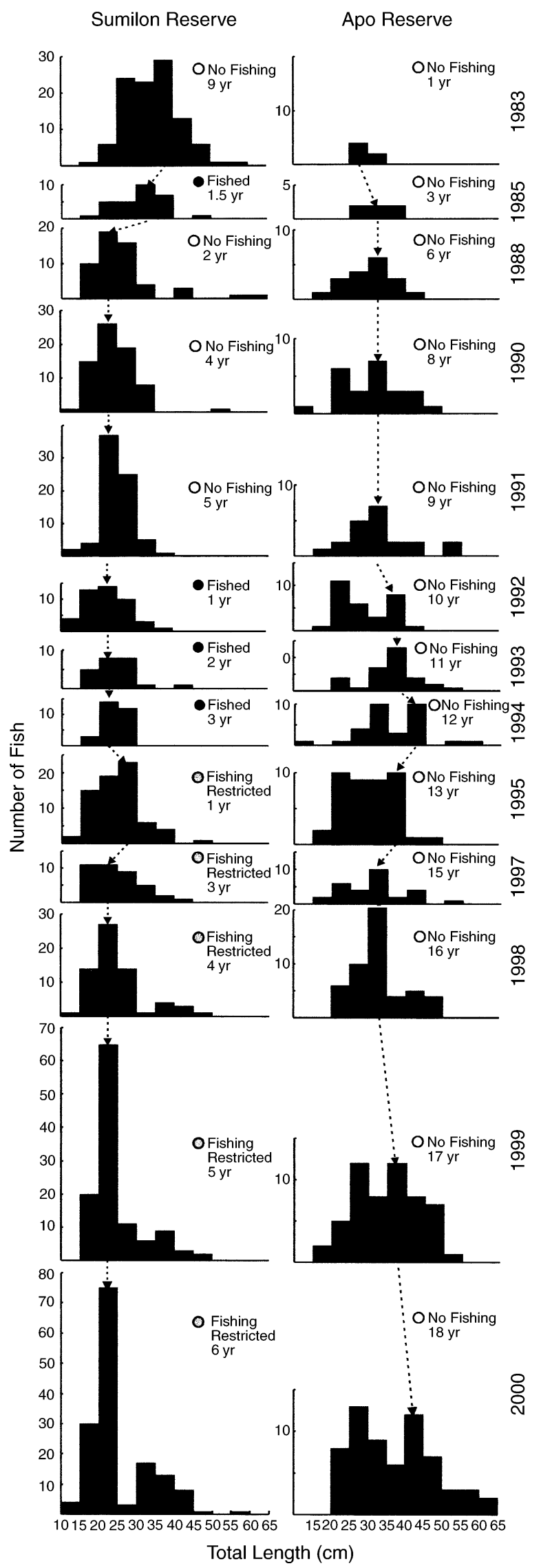

casions during reserve protection (Sumilon reserve 1997-2000, Apo reserve 1988-2000). All three significant density declines occurred when protection from fishing was removed (Sumilon reserve 1983-1985, 1991-1993; Sumilon nonreserve 1991-1994). Biomass responses following removal of protection were similar to those of density, but occurred more slowly when reserve status was applied (Fig. 4, Table 3). This represents some of the best evidence currently available that application of marine-reserve status causes increases in abundance of target species.

The density of large predatory fish increased significantly twice in areas open to fishing (Sumilon nonreserve 1994-1997; Apo nonreserve 1991-1998). The first occurrence resulted from very good recruitment of Cephalopholis argus in 1995. The density of large predatory fish in Sumilon nonreserve had declined back to levels less than those in 1983 (open to fishing long term) by 2000 (Fig. 3). The significant increase in density and biomass of large predatory fish in the Apo nonreserve (Figs. 3 and 4) may have resulted from a combination of two factors-a more restrictive management plan and/or spillover from protected areas. In 1986 a Marine Management Plan was put into place that banned nonresidents from fishing at Apo Island (Russ and Alcala 1999) and banned fishing practices deemed detrimental to long-term sustainability of fisheries (e.g., explosives, poisons, drive nets, small-mesh nets, spearing on Scuba). Furthermore, as income increased from tourism generated by the Apo reserve, people on Apo Island fished less (Russ and Alcala 1999, Maypa et al. 2002), and by 2000 had stopped using traps and gill nets (Maypa et al. 2002). Spillover of fish from the reserve into the nonreserve (Russ and Alcala 1996b) could have contributed to the rise also (Figs. 3 and 4).

Rates of decline in both density and biomass were invariably rapid, occurring in 2-3 years following removal of reserve status twice within Sumilon reserve and once at the Sumilon nonreserve (Figs. 3 and 4). Thus the rate of loss of density and biomass when a reserve is first opened to fishing is much faster than the rate of gain when the reserve is first closed. Similar observations are often made in experimental studies of the interaction between predators and prey. Predators introduced into previously predator-free systems can often cause dramatic declines in abundance of prey and changes to the structure of the community (Jones 1982). The effects of experimental predator removals

FIG. 5. Size structure of large predatory reef fish (Families Serranidae [Epinephelinae], Lutjanidae, Lethrinidae, and Carangidae as a group, excluding Macolor spp. at Apo) in the Sumilon and Apo reserves at the 13 sampling times during 1983-2000. Dashed arrows show shifts in modal size over time. The protection status of each reserve at each time is shown. 
a) Density

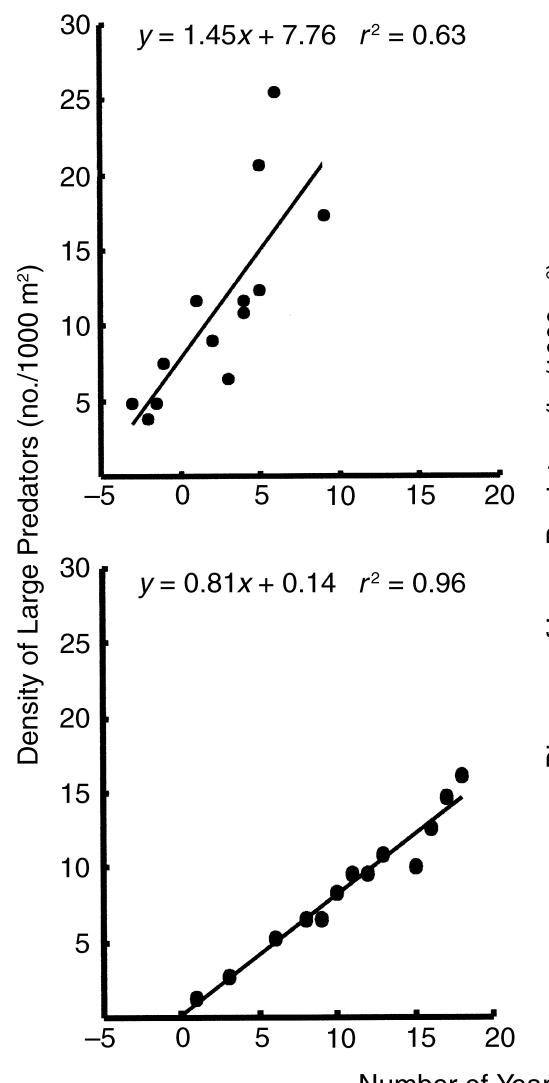

b) Biomass
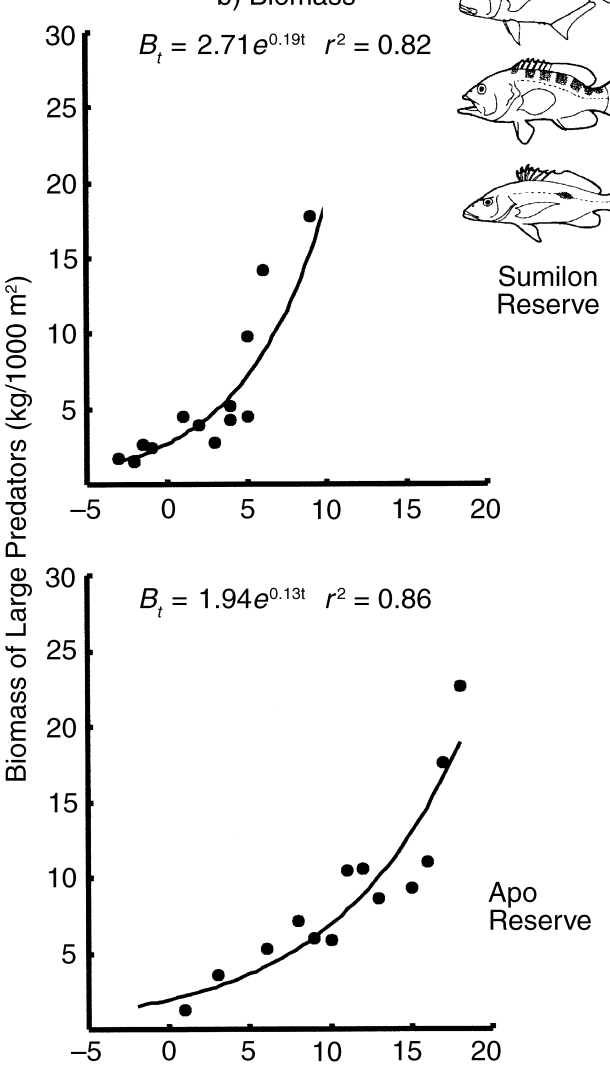

FIG. 6. Relationships between (a) mean density and (b) mean biomass of large predatory reef fish (Families Serranidae [Epinephelinae], Lutjanidae, Lethrinidae, and Carangidae as a group) and years of marine-reserve protection at Sumilon and Apo islands. Negative years of protection indicates years open to fishing. $B=$ biomass at time $t$ ( $t$ in years).

can often be much more slow and subtle (Hixon 1991). The observations of differential rates of decline and recovery in this study also have considerable management significance. The data argue for permanent, longterm protection in order to achieve fishery benefits like spillover and the recruitment effect (Russ 2002). They argue against the strategy of "rotational harvests," since benefits accrue slowly but are lost quickly.

Different patterns of increase were observed for density and biomass of large predatory fish following application of marine-reserve status (Fig. 6). Significant positive linear correlations of mean density of large predators against years of reserve protection were recorded at both reserves. The rate of increase of density was considerably higher at Sumilon reserve than Apo reserve over the $17 \mathrm{yr}$ of the study (1.45 cf. $0.81 \mathrm{fish}$ per $1000 \mathrm{~m}^{2}$ per year). This may be related to Sumilon reserve being more structurally complex than Apo reserve (Russ and Alcala 1998). It may also reflect a greater rate of larval supply to Sumilon than Apo reserve, although no evidence is available to support this suggestion. If differences do exist in rates of larval supply to and from such islands, knowledge of such differences would be useful criteria for site selection of future marine reserves. Despite differences in the rate of increase, the maximum density attained at each reserve at the maximum durations of reserve protection were similar (17 and 16 fish per $1000 \mathrm{~m}^{2}$ at 9 and 18 $\mathrm{yr}$ of protection for Sumilon and Apo reserves, respectively). Mean biomass of large predatory fish increased exponentially with years of reserve protection (Fig. 6). However, the exponents were $<0.2$ at both reserves (time unit in years), and biomass recovery was initially slower than that of density. There was little evidence of either density or biomass approaching an asymptote (Fig. 6). Russ (2002) concluded that no study has yet documented a clear asymptote in abundance of large predatory fish in a marine reserve.

The majority of the evidence that marine-reserve application increases abundance of target species still involves comparisons of abundance at the one time at sites with and without marine-reserve protection (Halpern and Warner 2002, Russ 2002, Halpern 2003). This paucity of long-term temporal monitoring of recovery rates in marine reserves has been stressed recently by both Jennings (2001) and Russ (2002). In a compre- 
hensive review of the patterns and predictions of population recovery in marine reserves, Jennings (2001: 227 ) concluded that "Empirical measures of recovery rates are scarce." Russ (2002) summarized the results of nine studies that included spatial and temporal comparisons of abundance of large predatory reef fish at reserve and fished locations. Most of the studies were of relatively short duration (1-3 yr). Only three studies had monitored for durations of 6-11 yr (Cole et. al. [1990] at Leigh reserve in New Zealand, McClanahan and Kaunda-Arara [1996] at Malindi reserve in Kenya, and Russ and Alcala [1996a] at Sumilon and Apo reserves, Philippines). Rapid rates of increase in abundance, expressed as [(final density/initial density)/by duration of reserve monitoring], invariably were reported by short-term studies. The most spectacular of these were an 8.4-fold increase in density of serranids at Pamilacan reserve, Philippines, over one year (White 1988) and a 13.5-fold increase in biomass of lethrinids in the Mombasa National Park, Kenya, over three years (McClanahan and Kaunda-Arara 1996). Such data may result from very successful recruitment soon after closure of a reserve (see Russ and Alcala 1996a, Russ et al. 1996, this study). The three studies with a reasonable duration of monitoring (6-11 years) - Leigh, Malindi, Sumilon, Apo and Sumilon nonreserve)—all had relatively low figures for [(final density/initial density)/ duration of reserve monitoring] (0.3-0.7), indicating that longer-term monitoring is more likely to indicate less rapid average rates of increase. The density of large predatory fish increased at these five reserves by a factor of 3.9 over a mean period of monitoring of nine years.

The present study demonstrated that application of marine-reserve status was the cause of increases in abundance of large predatory fish, and that removal of reserve status caused significant decreases in abundance. This demonstration was made possible by the variable reserve status over time at two sites, and the relatively consistent reserve status over time at two other sites (Fig. 2). The study is effectively an adaptivemanagement experiment (sensu Hilborn and Walters 1992), in which "reserve treatment" has been applied and removed over time at replicate sites. Such a design reduces the probability of treatment $\times$ site interactions, since different treatments have been applied at some of the same sites at different times. Perhaps a more appropriate experimental design to unequivocally demonstrate effects of marine reserves on abundance of target organisms is a before-after, control-impact pair (BACIP) design, incorporating long-term measurements of abundance at replicate reserve and control pairs before and after application of reserve status (Russ 2002). However, the application and removal of reserve status over time at the Sumilon Island sites had advantages over a standard BACIP design. The "natural" experiment (Fig. 2) was a very informative one, in this case, since it measured rates of both recovery and decline of abundance.

In conclusion, application of no-take marine-reserve status resulted in four significant increases in density of large predatory fish at three different sites in this study. Two other significant increases were recorded during protection. Although two of these significant increases were rapid ( $2 \mathrm{yr}$ ), invariably associated with recruitment pulses, three required 4-6 yr of protection. Removal of marine-reserve status resulted in rapid (2$3 \mathrm{yr}$ ), significant decreases in density of large predatory fish on three occasions. Rates of biomass increase following application of reserve status were usually slower than those of density. Individual fish can be added rapidly to reserves by recruitment, but fish need time to grow to large size. Rates of decrease of biomass and density were rapid following removal of reserve status. This represents some of the best evidence currently available that application of marine-reserve status causes increases in abundance of target species. Patterns of increase of large predatory fish were linear for density, but exponential for biomass at Sumilon and Apo reserves. Mean density and biomass were still increasing after 9 and 18 years of marine-reserve protection at Sumilon and Apo reserves, respectively, with little evidence of either density or biomass approaching an asymptote. At Sumilon Island, unregulated fishing over 1.5-3 yr on three occasions eliminated density and biomass gains accumulated over 5-9 yr of marine reserve protection. This emphasizes the need for longterm, continuous, enforcement of reserve status before expectations of increased spawning-stock biomass of fished species within reserves, and maintenance of fisheries external to reserves, can be achieved.

\section{ACKNOWLEDGMENTS}

Some financial support for this research was provided by the United Nations Environment Program and the Natural Resources Management Center of the Philippines (1983), the Great Barrier Reef Marine Park Authority (1985), and a Pew Fellowship (1999-2000) jointly held by the authors. Thanks to all of the staff at the Silliman University Angelo King Center for Research and Environmental Management and the Marine Laboratory, Silliman University, Dumaguete City, Philippines. Thanks also to the people of Apo Island and the various caretakers at Sumilon Island. P. Munday and two anonymous reviewers made valuable improvements to the manuscript.

\section{Literature Cited}

Alcala, A. C., and T. Luchavez. 1981. Fish yield of the coral reef surrounding Apo Island, central Visayas, Philippines. Pages 69-73 in E. D. Gomez, C. E. Birkeland, R. W. Buddemeier, R. E. Johannes, J. A. Marsh, and R. T. Tsuda, editors. Proceedings of the Fourth International Coral Reef Symposium [18-22 May 1981, Manila, Philippines]. Marine Sciences Center, University of the Philippines, Quezon City, Philippines.

Alcala, A. C., and G. R. Russ. 1990. A direct test of the effects of protective management on abundance and yield of tropical marine resources. Journal du Conseil Internationale pour 1'Exploration de la Mer 47:40-47. 
Allison, G. W., J. Lubchenco, and M. H. Carr. 1998. Marine reserves are necessary but not sufficient for marine conservation. Ecological Applications 8(Supplement):S79S92.

Bellwood, D. R. 1988. Seasonal changes in the size and composition of the fish yield from reefs around Apo Island, central Philippines, with notes on methods of yield estimation. Journal of Fish Biology 32:881-893.

Bohnsack, J. A. 1996. Maintenance and recovery of reef fish productivity. Pages 283-313 in N. V. C. Polunin and C. M. Roberts, editors. Reef fisheries. Chapman and Hall, London, UK.

Bohnsack, J. A. 1998. Application of marine reserves to reef fisheries management. Australian Journal of Ecology 23: 298-304.

Cole, R. G., A. M. Ayling, and R. G. Creese. 1990. Effects of marine reserve protection at Goat Island, northern New Zealand. New Zealand Journal of Marine and Freshwater Research 24:197-210.

Dayton, P. K., E. Sala, M. J. Tegner, and S. F. Thrush. 2000. Marine protected areas: parks, baselines, and fishery enhancement. Bulletin of Marine Science 66:617-634.

Dugan, J. E., and G. E. Davis. 1993. Applications of marine refugia to coastal fisheries management. Canadian Journal of Fisheries and Aquatic Sciences 50:2029-2042.

Froese R., and D. Pauly. 1997. Fishbase 97: concept, design and data sources. International Center for Living Aquatic Resources Management, Manila, Philippines.

Halpern, B. S. 2003. The impact of marine reserves: do reserves work and does reserve size matter? Ecological Applications 13(Supplement):S117-S137.

Halpern, B. S., and R. R. Warner. 2002. Marine reserves have rapid and lasting effects. Ecology Letters 5:361-366.

Hilborn, R., and C. J. Walters. 1992. Quantitative fisheries stock assessment. Choice, dynamics and uncertainty. Chapman and Hall, New York, New York, USA.

Hixon, M. A. 1991. Predation as a process structuring coral reef fish communities. Pages 437-474 in P. F. Sale, editor. The ecology of fishes on coral reefs. Academic Press, San Diego, California, USA.

Jennings, S. 2001. Patterns and prediction of population recovery in marine reserves. Reviews in Fish Biology and Fisheries 10:209-231.

Jones, G. P., R. C. Cole, and C. N. Battershill. 1992. Marine reserves: do they work? Pages 29-45 in C. N Battershill, editor. Proceedings of the Second International Temperate Reef Symposium [Auckland, New Zealand]. National Institute of Water and Atmospheric Research, Marine, Wellington, New Zealand.

Jones, R. 1982. Ecosystems, food chains and fish yields. ICLARM Conference Proceedings 9:195-239.

Maypa, A. P., G. R. Russ, A. C. Alcala, and H. P. Calumpong. 2002. Long-term trends in yield and catch rates of the coral reef fishery at Apo Island, central Philippines. Marine Freshwater Research 53:207-213.

McClanahan, T. R. 2000. Recovery of a coral reef keystone predator, Balistapus undulatus, in East African marine parks. Biological Conservation 94:191-198.

McClanahan, T. R., and B. Kaunda-Arara. 1996. Fishery recovery in a coral-reef marine park and its effect on the adjacent fishery. Conservation Biology 10:1187-1199.
Murray, S. N., et al. 1999. No-take reserve networks: sustaining fishery populations and marine ecosystems. Fisheries 24(11):11-25.

NRC [National Research Council]. 2001. Marine protected areas: tools for sustaining ocean ecosystems. National Academy Press, Washington, D.C., USA.

Ralston, S., and J. J. Polovina. 1987. Tropical snappers and groupers: biology and fisheries management. Westview Press, Boulder, Colorado, USA.

Roberts, C. M. 1997. Ecological advice for the global fisheries crisis. Trends in Ecology and Evolution 12:35-38.

Roberts, C. M., and N. V. C. Polunin. 1991. Are marine reserves effective in management of reef fisheries? Reviews in Fish Biology and Fisheries 1:65-91.

Rowley, R. J. 1994. Marine reserves and fisheries management. Aquatic Conservation 4:233-254.

Russ, G. R. 1985. Effects of protective management on coral reef fishes in the central Philippines. Pages 219-224 in B. Delesalle, C. Gabrie, R. Galzin, M. Harmelin-Vivien, J. L. Toffart, and B. Salvat, editors. Proceedings of the Fifth International Coral Reef Symposium [27 May-1 June 1985, Tahiti, French Polynesia. Antenne Museum-Ephe, Tahiti, French Polynesia.

Russ, G. R. 2002. Yet another review of marine reserves as reef fisheries management tools. Pages 421-443 in P. F. Sale, editor. Coral reef fishes: dynamics and diversity in a complex ecosystem. Academic Press, San Diego, California, USA.

Russ, G. R., and A. C. Alcala. 1989. Effects of intense fishing pressure on an assemblage of coral reef fishes. Marine Ecology Progress Series 56:13-27.

Russ, G. R., and A. C. Alcala. 1996a. Marine reserves: rates and patterns of recovery and decline in abundance of large predatory fish. Ecological Applications 6:947-961.

Russ, G. R., and A. C. Alcala. 1996b. Do marine reserves export adult fish biomass? Evidence from Apo Island, central Philippines. Marine Ecology Progress Series 132:1-9.

Russ, G. R., and A. C. Alcala. 1998. Natural fishing experiments in marine reserves 1983-1993: community and trophic responses. Coral Reefs 17:383-397.

Russ, G. R., and A. C. Alcala. 1999. Management histories of Sumilon and Apo marine reserves, Philippines, and their influence on national marine resource policy. Coral Reefs 18:307-319.

Russ, G. R., D. C. Lou, and B. P. Ferreira. 1996. Temporal tracking of a strong cohort in the population of a coral reef fish, the coral trout, Plectropomus leopardus (Serranidae: Epinephelinae), in the central Great Barrier Reef, Australia. Canadian Journal of Fisheries and Aquatic Sciences 53: 2745-2751.

Underwood, A. J. 1981. Techniques of analysis of variance in experimental marine biology and ecology. Oceanography and Marine Biology Annual Review 19:513-605.

White, A. T. 1988. The effect of community-managed marine reserves in the Philippines on their associated coral reef fish populations. Asian Fisheries Science 2:27-41.

White, A. T., and G. C. Savina. 1987. Reef fish yield and non-reef catch of Apo Island, Negros, Philippines. Asian Marine Biology 4:67-76.

Winer, B. J. 1971. Statistical principles on experimental design. McGraw-Hill, New York, New York, USA. 